\title{
LA NOVELA CORTA Y EL CINE: ¿UN FORMATO IDEAL?
}

\section{Stefano Tedeschi}

Sapienza Università di Roma

stefano.tedeschi@uniromal.it

Resumen: La relación entre la novela corta como género y el cine se ha desarrollado a lo largo del siglo XX en formas complejas alrededor de algunos problemas generales sobre la cuestión del tiempo en ambas expresiones artísticas. Se ha ido produciendo, además, una serie de textos "híbridos", que fueron pensados para el cine, para convertirse sucesivamente en textos narrativos independientes. A partir de una consideración de tipo cuantitativo sobre el número de novelas cortas hispanoamericanas que han sido adaptadas para la industria cinematográfica, sobre todo en la segunda mitad del siglo XX, se investigará si la novela corta es el formato ideal para la transposición de obras literarias al cine.

Palabras clave: Álvaro Mutis, novela corta, cine y literatura

\begin{abstract}
The relationship between the short novel and movies has developed throughout the $20^{\text {th }}$ century in complex forms, around some general problems about the question regarding time in both artistic expressions. It has also produced a series of "hybrid" texts, which were intended for movies to become afterwards independent narrative texts. Starting from a quantitative consideration on the number of Spanish American short novels adapted for film industry, especially in the second half of the $20^{\text {th }}$ century, I investigate if the short novel is the ideal format for the transposition of literary works to the cinema.
\end{abstract}

Keywords: Álvaro Mutis, short novel, movies and literature

DOI: https://doi.org/10.24029/lejana.2017.10.167

Recibido: el 30 de junio de 2017

Aceptado: el 13 de octubre de 2017

Publicado: el 4 de noviembre de 2017 
La relación entre la novela corta como género y el cine se ha desarrollado a lo largo del siglo $\mathrm{XX}$ en formas complejas, no del todo lineales, que buscaré seguir en las páginas que siguen, individuando algunos problemas generales sobre la cuestión del tiempo en ambas expresiones artísticas, y analizando la construcción de la narración en una serie de textos "híbridos", que fueron pensados para el cine para convertirse sucesivamente en textos narrativos independientes, y que a veces volvieron a la pantalla bajo la dirección de otros nombres respecto a los que se habían pensado inicialmente. ${ }^{1}$

Mi punto de partida ha sido una consideración de tipo cuantitativo sobre el número de novelas cortas hispanoamericanas que han sido adaptadas para la industria cinematográfica, sobre todo, en la seguna mitad del siglo XX. Desde algunos años estamos construyendo en mi Departamento, con la ayuda de nuestros estudiantes y técnicos informáticos, una base de datos sobre las obras literarias hispanoamericanas que conocieron versiones fílmicas (y que esperamos poner a disposición de la comunidad científica en un futuro no demasiado lejano). Según los datos recogidos hasta ahora, y que suman un total de casi 450 películas, resulta que un $25 \%$ de los textos individuados fueron novelas cortas, un $40 \%$ novelas "tradicionales", y el restante $35 \%$ se divide entre cuentos y piezas teatrales. Si consideramos que la novela corta no representa un género mayoritario en la producción literaria, aun con todas las posibles consideraciones que se pueden hacer sobre su exacta definición, estas cifras - aunque merezcan ser afinadas - muestran cómo esta tiene un lugar sobresaliente entre las elecciones de guionistas y directores al momento de seleccionar un texto para hacer de él una adaptación cinematográfica.

Nos podríamos entonces preguntar si esta situación es el fruto de una casualidad, un simple accidente estadístico, o tiene una razón más profunda, relacionada con la naturaleza misma de la novela corta, y si la respuesta a esta pregunta nos puede ayudar a definir mejor este género, en el proceso de hibridación con otra forma de narrativa. Me parece claro que en esta relación cruzada entre novela corta y cine juega un papel crucial la cuestión del tiempo, en su doble dimensión de tiempo de fruición de la obra artística y de organización temporal de los eventos que se presentan en el texto.

Por su naturaleza, ambas formas se pueden gozar durante un tiempo definido: las novelas cortas se consiguen leer en un tiempo relativamente breve - aunque no exijan obligatoriamente este tipo de lectura, como nos recuerda Luis Arturo Ramos (Ramos, 2011: 42) —, mientras que la narración cinematográfica se encuadra — salvo casos especiales— en una dimensión temporal claramente definida por su condición de producto industrial y comercial. En algunos casos se puede dar la circustancia de que el tiempo de lectura de una novela corta coincida con la duración habitual de una película, como se puede verificar con algunas famosas novelas cortas llevadas a la pantalla grande. ${ }^{2}$

Al interior de estas medidas definidas, ambas formas tienen que, sin embargo, concentrar una fábula a veces muy enredada, que abarca una dimensión temporal mucho más amplia, y para la novela corta valen nuevamente las palabras de Ramos:

\footnotetext{
${ }^{1}$ Este texto nace de la experiencia didáctica llevada a cabo con mis estudiantes de grado del curso 2016-2017, y que quisiera agradecer por su colaboración.

${ }^{2}$ Es el caso, por ejemplo, de El coronel no tiene quien le escriba de Gabriel García Márquez, de El gallo de oro de Juan Rulfo, o de Aura de Carlos Fuentes: en estos últimos dos ejemplos, el tiempo de lectura es posibilemente menor que el de la visión de las respectivas películas.
} 
Mis textos narran lo que le sucede a un personaje, a veces a dos, como por lo general ocurre en el cuento; pero siempre, como sucede en el cuento, montados en una misma línea argumental que los significa y potencia. No obstante, para construir aquélla y perfilar a éste, construyo personajes coestelares y alimento la trama con hilos narrativos llevados a evitar que el protagonista quede diluido en el soliloquio del discurso propio y de las acciones aisladas.

Esta estrategia no sólo tiene el objetivo de fortalecer al personaje central, sino de enriquecer su historia con afluentes que pretendo válidos e interesantes en sí mismos; pero cuya función primordial es nutrir con asomos de realidad y verosimilitud el argumento central que vertebra al texto de principio a fin.

Lo anterior, a semejanza de lo que ocurre en las novelas (en las buenas novelas al menos), donde una historia nunca discurre solitaria y en despoblado. Por las mismas razones, incluyo la descripción más o menos minuciosa del ambiente exterior a fin de que el protagonista se desenvuelva y signifique. (Ramos, 2011: 44)

Esta peculiaridad de la novela corta se da gracias a la condensación de un desarrollo temporal a veces muy amplio, efecto logrado no solo gracias al tradicional uso de elipsis y compendios narrativos, sino a cortes y saltos temporales mucho más complejos, como analepsis y prolepsis, o incluso a una disposición de los hechos fuera de cualquier lógica consecutiva. Para alcanzar esta concentración, los escritores han ido aplicando para la forma de la novela algunas técnicas aprendidas de sus frecuentaciones del mundo cinematográfico, sea como espectadores que como profesionales, como nos recuerda Mario Vargas Llosa en una entrevista sobre su relación con el cine:

Creo que, fundamentalmente, la narración cinematográfica agiliza extraordinariamente el tratamiento del tiempo en la ficción narrativa. El cine nos acostumbra a ver el tiempo como un espacio, algo en el cual uno puede desplazarse con mucha libertad, saltando hacia el pasado, por ejemplo, y del pasado, saltando hacia el presente o al futuro, a una velocidad instantánea, algo que la imagen permite muy fácilmente identificar. En la literatura esto no existía hasta el cine. Con el cine, la literatura empieza a tratar el tiempo con una libertad, con una flexibilidad, porque se dirige a un público que está acostumbrado a esos saltos temporales gracias a las películas. $^{3}$

En efecto, si analizamos las obras contenidas en la plataforma La novela corta: una biblioteca virtual (http://www.lanovelacorta.com/), podemos advertir como los textos presentados en la primera parte (1872-1922) van evolucionando desde una estructura temporal bastante lineal (Justo Sierra, Ignacio Manuel Altamirano, Féderico Gamboa), hasta formas ya más complejas con la aparición de novelas de corte modernista (Manuel Othon, Amado Nervo, Efrén Rebolledo), aunque todavía no se alcanza una co-presencia de diversos niveles temporales. En cambio, los textos presentes en la sección Novelas en campo abierto (19222000) muestran ya una sensible evolución hacia estructuras de mayor compeljidad; el primer corte se da claramente con las novelas de vanguardia (Arqueles Vela, Salvador Novo, Gilberto Owen, Efrén Hernández) y se ejemplifica en la trayectoria que lleva Mariano Azuela de Andrés Pérez Maderista (1911) a La Malhora (1923). Aquí se realiza la ruptura de todo fundamento de causalidad temporal, junto a la inserción masiva de elementos de tipo visual, otra consecuencia de la irrupción del cine en la cultura del siglo XX. Cuando, sucesivamente, los autores volverán a una escritura menos experimental, no será para realizar una suerte de

\footnotetext{
3 La entrevista es una en video, que se puede consultar en el siguiente enlace: https://www.youtube.com/watch?v=je35TSpPA0A (última consulta: 18/10/2017). La cita corresponde a los mínutos 4.10-5.20.
} 
vuelta al pasado, sino más bien se producirán formas narrativas con estructuras discursivas más elaboradas, como por ejemplo, en los textos de Sergio Pitol, Carmen Boullosa o Luis Arturo Ramos.

Este singular y novedoso tratamiento del tiempo — que, como observa Vargas Llosa, se puede observar en cualquier tipo de novelas - se vuelve evidentemente decisivo en la novela corta, cuando la condensación puede alcanzar niveles muy altos, acogiendo al mismo tiempo una extensión temporal mucho más amplia de la que ocurre en los cuentos.

Acaso sea esta la razón por la cual muchos directores y guionistas consideran la novela corta como el género más conveniente para la trasposición cinematográfica, dado que en sus páginas ya se encuentra realizada aquella operación de corte y resumen que muchas veces resulta necesaria al momento de realizar la adaptación de obras literarias. Paz Alicia Garcíadiego recuerda algo similar hablando de su trabajo de trasposición de El coronel no tiene quien le escriba:

Cuando la hice mía, cuando el Coronel y su mujer hablaron con mi voz y con la de los míos, cuando arteramente me la apropié, la robé, comencé a escribirla. Pocas veces me había enfrentado a un trabajo tan suave, tan sencillo, tan natural, tan placentero [...]. El coronel no tiene quien le escriba es una historia que se cuenta sola. Tiene la naturalidad, la simplicidad y la elegancia de la perfección. [...] Empecé a leer la novela y escribí el guión de un tirón y completé justo las 97 páginas, medidas y calibradas. (Garciadiego, 1999: 41)

Otra vertiente del problema se puede observar en una sugestiva coincidencia terminológica: en los artículos reunidos en los tres volúmenes de ensayos bajo el título de Una selva tan infinita (Jiménez Aguirre, 2011-2014), los términos que se repiten al momento de intentar ofrecer una definición teórica del género llamado novela corta — condensación, densidad, tensión, cadencia, ritmo - son muy parecidos — cuando no los mismos — a los que los guionistas utilizan cuando hablan de su propia experiencia de escritura; por otro lado, no podemos olvidar que muchos autores de novelas cortas fueron guionistas a lo largo de su carrera o en su etapa temprana, incluso durante toda su vida. El "guion de autor", como nos recuerda Alessandro Rocco en su estudio (2009), tiene una fuerte vocación literaria, ya que se sitúa en un territorio intermedio donde literatura y cine se encuentran necesariamente, aunque el guion conserve por lo menos dos aspectos propios que lo diferencian de otras formas de escritura: se trata, en efecto, de textos producidos para transmitir una "visión" de una narración para que otros la transformen en una película, y que inicialmente se dirigen a un grupo de lectores muy reducido y muy claramente individuable. Sin embargo, la experiencia de la escritura guionística contribuyó, para más de un autor, a la evolución hacia formas de escritura más híbridas y cercanas a una narración de tipo fílmico. Podría ser una interesante pista de investigación interrogarnos acerca de la posibilidad de que el "guion de autor" sea considerado como un género independiente y paralelo al de la novela corta, para encontrar parecidos y diferencias entre ellos, pero no es esta la tarea que ahora me incumbe.

La pregunta inicial se va perfilando, en todo caso, con más precisión: si notamos, en efecto, cómo se realizan las relaciones binarias entre novela corta y cine en formas de reciprocidad, nos podemos entonces interrogar si la progresiva afirmación de la narración cinematográfica como narración paradigmática del siglo XX —en sus múltiples dimensiones de narración multimedia - se pueda relacionar con la evolución de la novela corta en las últimas décadas del mismo siglo. 
Este posible vínculo se puede estudiar en una serie de casos de estudio de suma relevancia para nuestra investigación: se trata de textos nacidos para el cine o a lado de la producción cinematográfica, y que, por diferentes razones, se volvieron novelas cortas. Tenemos varios ejemplos de este tipo, como El gallo de oro de Juan Rulfo, La increíble y triste historia de la cándida Eréndira y de su abuela desalmada de Gabriel García Márquez, La mansión de Araucaíma de Álvaro Mutis, Fresa y chocolate de Senel Paz, o el caso muy peculiar de Ardiente paciencia de Antonio Skármeta, pensado como un guion, transformado en novela, para finalmente volver a la pantalla en la versión de Michael Radford, una película cuyo éxito internacional causó el cambio del título de la misma obra literaria. ${ }^{4}$ No se podrán olvidar asimismo aquellas novelas cortas que, según el testimonio de los mismos autores, nacieron de la experiencia de la visión de una película, como la ya mencionada El coronel no tiene quien le escriba, relacionada con el neorrealismo de Vittorio de Sica, ${ }^{5}$ o como Aura, cuya primera idea nació, como nos recuerda Fuentes, de la visión de una película japonesa en un cine de París. ${ }^{6}$

Entre todos estos ejemplos — que seguramente podrían incrementarse - un caso de estudio particularmente interesante resulta La mansión de Araucaíma de Álvaro Mutis, novela corta publicada en 1973, aunque su historia textual tenga una trayectoria antecedente bastante singular. Como ha contado el mismo Mutis en diferentes entrevistas, la novela nació como respuesta a una especie de provocación de Luis Buñuel acerca de la posibilidad de que pudiera existir una novela gótica fuera de sus consuetas ambientaciones (castillos medievales, nieblas, frío, fantasmas etc.). Cuenta Mutis lo siguiente:

Quiero hacer una novela gótica pero en tierra caliente [...]. Buñuel me contestó que no se podía, que era una contradicción, ya que la novela gótica para él tendría que suceder en un ambiente gótico. (Mutis, 1989)

Yo le dije que no se había escrito una novela gótica en tierra caliente, en el trópico, y Luis me dijo que era imposible hacerla porque al cambiar el escenario convencional la novela dejaba de ser gótica. Le pedí 15 días para demostrárselo como tocaba, y allí llegué con La mansión de Araucaíma. A la tarde siguiente me llamó por teléfono y me dijo que tenía toda la razón. (Rodríguez Amaya, 1996: 233)

A pesar de las esperanzas del escritor colombiano, Buñuel nunca llevó al cine este texto suyo, aunque este hubiera sido pensado y realizado justamente imaginando esta posibilidad:

También me dijo que quería hacer de la Mansión una película, y en realidad se entusiasmó con el proyecto. Le pedí que me permitiera reescribirla, pues lo que yo había hecho era llevarle un primer tratamiento para demostrarle que sí se podía. La pulí y la trabajé pensando en la pantalla grande. Creo que el lector puede darse cuenta de eso; primero están los personajes, luego la descripción del escenario y después los hechos. (Quiroz en Rodríguez Amaya, 1996: 236)

Según lo que nos dice el mismo autor, aquí incluso la organización del texto (trece cuadros breves que llevan como título los nombres de los personajes, sus sueños, la

\footnotetext{
${ }^{4}$ El caso ha sido estudiado por Irene B. Hodgson (2002) y por Roberta Previtera (2014).

${ }^{5}$ Gabriel García Márquez ha hablado muchas veces de su relación con el neorrealismo italiano, a partir de las reseñas publicadas en los años cincuenta, como por ejemplo la que escribió sobre la película Umberto D de Vittorio De Sica (1982).

${ }^{6}$ Carlos Fuentes habla de esto en un artículo de 1993.
} 
descripción del lugar y los hechos) nace de un proyecto imaginado para el cine, donde una unidad de lugar corresponde a una dilatación y diseminación del tiempo. Si en efecto, como afirma Julio Olaciregui, la definición del espacio respeta la unidad de lugar propria de una pieza teatral, en cambio, la dimensión temporal se presenta mucho más articulada: "Il faut souligner les rapports formels qu'entretient la construction du récit avec la structure d'une pièce de théâtre: la maison serait la scène (elle est abbandonnée à la fin) et les acteurs les personnages. Malgré l'ouverture qui signifie l'inclusion des rêves au milieu du récit, il y a une volonté de respecter l'unité de lieu et l'unité de l'action" (Olaciregui, 1983: 5). ${ }^{7}$

Si realmente la Mansión tiene estas características espaciales, por otro lado, es un lugar fuera del tiempo, o mejor dicho, dentro de un tiempo suspendido, donde han ido a parar personajes que han vivido otras vidas en otras épocas, y que por una especie de encantamiento no pueden ya escapar de una situación que los ha atrapado casi sin remedio. La aparición de la joven Ángela rompe este embrujo, y su sacrificio causará la muerte de dos de los personajes —una de ellos es la Machiche, la "bruja" que es la causa del encantamiento- y la huida/liberación de los otros. La narración se construye gracias a una serie de prolepsis / analepsis cruzadas, y a la inserción de tres "sueños" que abren una perspectiva onírica de corte fantástico, y se resuelve en un desenlace trágico y rapidísimo. El mismo Mutis explica las razones de esta elección con las siguientes palabras: "La historia que se cuenta es muy brutal, sumamente violenta, y es narrada en forma muy escueta. Había otra manera de escribirla, que era desarrollando plenamente todo lo narrado, pero no quise hacerlo así, primero porque soy un tremendo perezoso, segundo porque quería condensar la violencia lo más posible, producir un relato casi plástico dentro de lo tropical" (Sheridan, 1976: 32). Dejando aparte la coquetería de la pereza como explicación extra-literaria, me parece que el segundo motivo — la voluntad de condensar la violencia — constituye el enlace entre la página escrita y su origen cinematográfica.

Si analizamos las pocas líneas en que se condensa el drama de los habitantes de la Mansión, podemos observar cómo se realiza en la escritura de Mutis aquella tendencia hacia una escritura de tipo audiovisual que Eduardo García Aguilar ya evidenció estudiando algunas de la novelas cortas de García Márquez (García Aguilar, 1984). Toda la acción se condensa en lo siguiente:

A la mañana siguiente el guardián entró temprano al cuarto de los aparejos y encontró el cuerpo de Ángela colgando de una de las vigas. Se había ahorcado en la madrugada subiéndose a una silla que arrojó con los pies, luego de amarrarse al cuello una recia soga.

$[\ldots]$

Entre el fraile y Don Graci lavaron el cadáver con una infusión de hojas de naranjos, indicada, según el dueño, para detener la descomposición, y lo envolvieron luego en una sábana. Estaban terminando su tarea cuando oyeron dos disparos provenientes del segundo patio. Se escuchó luego un forcejeo violento, un golpe seco y después reinó el tibio silencio vespertino. El fraile y Don Graci acudieron precipitadamente y desde el corredor vieron cómo en el patio el guardián sujetaba contra el suelo al sirviente con una llave de judo que lo mantenía inmóvil. A un lado la Machiche, tendida en el empedrado, agonizaba con dos grandes heridas en el

\footnotetext{
7 "Hay que subrayar las relaciones formales que existen entre la costrucción del relato y la estructura de una pieza teatral: la mansión sería la escena (que al final se abandona) y los personajes serían los actores. A pesar de la apertura que representa la incursión de los sueños en medio del relato, existe una voluntad de respetar la unidad de lugar y tiempo" (traducción mía).
} 
pecho de las que manaba, a cada estertor, una sangre oscura y abundante. Más allá yacía el piloto con el cráneo grotescamente destrozado. (Mutis, 1988 [1973]: 68-70)

La precisión y la concisión de la representación permiten al lector "ver" la escena sin necesidad de emplear otros instrumentos narrativos o retóricos, e incluso el uso de los adjetivos y de los adverbios — tan relevante en las futuras novelas del ciclo de Maqrollqueda aquí reducido a una mera función descriptiva, que aprovecharán algunos años más tarde Julio Olaciregui y Carlos Mayolo en la versión cinematográfica de $1986 .{ }^{8}$ Por otro lado, el texto de La Mansión de Araucaíma pertenece todavía a la fase "poética" de la obra del autor colombiano, y la escritura de la novela denota esta cercanía a una forma de escritura que contenía desde siempre una fuerte carga visual, ${ }^{9}$ así como su inegable tendencia a emplear una absoluta economía verbal: el cruce entre poesía, narrativa y cine produce al final un texto cuya hibridez génerica propone al lector / espectador una enorme carga emotiva y, probablemente, su origen como proyecto fílmico permite que todos los componentes se combinen de manera muy eficaz.

El estudio de los otros textos antes mencionados nos podría llevar a conclusiones parecidas: sobre la relación entre el guin inicial de Eréndira y su transformación en novela ha escrito páginas de gran interés Alessandro Rocco (2014), mientras que, sobre El gallo de oro, la bibliografía ya es amplia y diversificada. ${ }^{10}$ Sin embargo, más allá de estos textos que constituyen solo una pequeña muestra dentro del corpus más vasto de la novela corta, se podría observar cómo influye en otros textos no nacidos alrededor de la industria cinematográfica la presencia de una narratividad de tipo fílmico, precisamente en la construcción del texto en cuanto género bien individuable. En este sentido, otro texto que se presenta muy peculiar es Concierto Barroco, la novela de Alejo Carpentier en que se juntan al mismo tiempo literatura, música y cine.

Si la relación con la música ha sido estudiada con resultados excelentes (Montoya, 2013), los posibles puntos de contacto con el séptimo arte emergen de un acercamiento que debe tener en consideración otros aspectos, como la capacidad de recrear espacios a través de sus evocaciones visuales —arquitectónicas y pictóricas - las referencias a elementos teatrales en la novela y, finalmente, la muy peculiar presencia de los evidentes anacronismos temporales.

Como se sabe, la novela transporta al lector en pocas páginas de México a Cuba, de Madrid a Venecia, para vislumbrar al final un retorno al punto de partida: los numerosos espacios geográficos se describen con la consabida riqueza barroca carpenteriana, y sin embargo no resultan fuera de lugar incluso en una novela corta, donde el lector y el crítico no se esperarían tanta profusión. Podemos observar el contraste entre La Habana y la Villa de Regla:

[...] se estaba en esta Villa de Regla, cuya pobre realidad de aldea rodeada de manglares acrecía, en el recuerdo, el prestigio de la ciudad dejada atrás, que se alzaba, con el relumbre de sus cúpulas, la suntuosa apostura de sus iglesias, la vastedad de sus palacios -y la floralías de

\footnotetext{
${ }^{8}$ La película de Carlos Mayolo, que tiene el mismo título de la novela, se produjo en 1986, basada en un guion de Julio Olaciregui y Philip Prestley.

${ }^{9}$ Fabrio Rodríguez Amaya ha escrito páginas notables sobre la relación entre poesía y novelas en Mutis (Rodríguez Amaya, 2000).

${ }^{10}$ Veáse por ejemplo el ensayo de Milagros Ezquerro, "El gallo de oro" (2006).
} 
sus fachadas, los pámpanos de sus altares, las joyas de sus custodias, la policromía de sus lucernarias- como una fabulosa Jerusalén de retablo mayor. Aquí, en cambio, eran calles angostas, de casas bajas, cuyas ventanas, en vez de tener cancelas de buen herraje, se abrían tras de varillas mal pintadas de blanco, bajo tejados que, en Coyoacán, apenas si hubiesen servido para cobijar gallineros o porquerizas. (Carpentier, 2015: 42)

La descripción en contrapunteo se construye por medio de la precisión de los sustantivos, más que por la abundancia de los adjetivos, casi en forma ecfrástica, como si nos encontráramos frente a una imagen, un cuadro, una fotografía o un fotograma, y gracias a este minucioso detallismo, la narración puede acoger dentro de sus breves páginas toda una serie de representaciones espaciales inconsuetas en las novelas cortas.

Las alusiones al teatro son múltiples a lo largo de la novela, y el capítulo VII se desarrolla todo al interior del teatro veneciano de Sant'Angelo, donde Antonio Vivaldi está ensayando su ópera Motezuma a la presencia del Amo criollo y del negro Filomeno. En todo el capítulo asistimos a una larga e irónica batalla entre el americano y el músico italiano sobre la verosimilitud de la representación artística, que Vivaldi concluye finalmente de manera tajante: "El indiano, aunque algo bajado de tono, seguía insistiendo: «La Historia nos dice...» -No me joda con la Historia en materia de teatro. Lo que cuenta aquí es la ilusión poética..." (Carpentier, 2015: 98).

Si lo que cuenta es la ilusión poética, se pueden entonces realizar aquellos imprevisibles saltos temporales que caracterizan Concierto Barroco, y que se dan en gran parte de manera desconcertante gracias a la mirada de los personajes que enfocan puntos del paisaje circustante:

[...] mientras el veneciano, remascando una tajada de morro de jabalí escabechado en vinagre, orégano y pimentón, dio algunos pasos, deteniéndose, de pronto, ante una tumba cercana que desde hacía rato miraba porque, en ella, se ostentaba un nombre de sonoridad inusitada en estas tierras. - "IGOR STRAVINSKY"- dijo, deletreando. (Carpentier, 2015: 81)

Al pasar frente al palacio Vendramin-Calergi notaron Montezuma y Filomeno que varias figuras negras - caballeros de frac, mujeres veladas como plañideras antiguas- llevaban hacia una góndola negra, un ataúd con fríos reflejos de bronce. - "Es de un músico alemán que murió ayer de apoplejía — dijo el Barquero, parando los remos-: ahora se llevan los restos a su patria. [...] Las figuras negras, envueltas en gasas y crespones, colocaron el ataúd en la góndola funeraria que, al impulso de pértigas solemnemente movidas, comenzó a navegar hacia la estación del ferrocaril donde, resoplando entre brumas, esperaba la locomotora de Turner con su ojo de cíclope ya encendido... (84-85)

Los acelerados saltos temporales se realizan delante de los protagonistas como de los lectores gracias a epifanías repentinas, visiones improvisas que llevan consigo una increíble carga de evocaciones culturales de todo tipo: musicales, literarias, pictóricas, para realizar en la página escrita una sorprendente hibridación, cuyo origen puede situarse quizás justamente en la capacidad sintética de la imagen y de la narración cinematográfica. No resulta extraño así que la versión fílmica de Paul Leduc renuncie totalmente al lenguaje hablado, para proponer un viaje hecho de imágenes y música, un experimento en el cual las palabras del texto se diluyen hasta desaparecer, para transformarse en pura imagen y sonido esencial, como afirma el mismo director: 
Me interesa el silencio en la música, en la literatura, en el cine. Creo que, además, nuestro cine ha caído a veces en una verborrea excesiva que no aporta nada.

El cine no es sólo imagen, es también sonido, sonido que puede ser los diálogos, puede ser silencio, puede ser de música o de ruidos incidentales, puede ser de gritos, pero se ha pensado poco en la banda sonora de nuestro cine latinoamericano. [...] Es la imagen en buena medida, pero también es en que momento entra esa imagen, cómo está compuesta: la escenografía, el vestuario, los objetos, la actuación, la atmósfera, todo eso tanbién está contando, diciendo cosas... (citado por Castillo, 2006: 136)

Para terminar, quisiera volver al conocido artículo de Ricardo Piglia sobre las características de la novela corta, que en los estudios sobre este género se cita muy a menudo (2006). En los diferentes textos que se han ido presentando a lo largo de estas páginas, algunas de las características que el crítico argentino considera esenciales en la definición del género (el secreto, el misterio, el suspenso) se pueden aplicar perfectamente al mismo tiempo a $L a$ Mansión de Araucaíma y a algunos aspectos de los otros textos si pensamos que, incluso en el de Carpentier, los saltos temporales se dan de manera surpresiva y misteriosa.

Creo, sin embargo, que en las novelas cortas que examiné en este ensayo nos encontraríamos frente a textos que no son, como afirma Piglia, "una forma posterior al cuento y anterior a la novela" (2006: 187) sino más bien delante de una evolución de la novela de corte tradicional, propiciada por la estrecha relación entre la narración literaria y la narrativa cinematográfica que se va dando a lo largo del siglo XX, produciendo formas híbridas de diferente tipo, entre las cuales la novela corta es quizás una de las más relevantes. ${ }^{11}$

\section{Bibliografía}

CARPENTIER, Alejo (2015) [1974]: Concierto Barroco. Ed. crítica. La Habana, Letras Cubanas (Biblioteca Alejo Carpentier).

CASTILlO, Luciano (2006): Carpentier en el reino de la imagen. La Habana, Ediciones Unión.

EZQUERRO, Milagros (2000): "El gallo de oro". Lecturas rulfianas. Guadalajara, Universidad de Guadalajara: 119-138.

FUENTES, Carlos: “On Reading and Writing Myself: How I Wrote Aura”. World Literature Today LVII/4, Carlos Fuentes Issue (1983): 531-539. DOI: https://doi.org/10.2307/40139102

GARCIADIEGO, Paz Alicia (1999): El Coronel no tiene quien le escriba. Guión cinematográfico. México, Universidad Veracruzana.

GARCÍA AGUILAR, Eduardo (1984): La tentación cinematográfica de Gabriel García Márquez. México, Universidad Nacional Autónoma de México.

GARCÍA MÁRQUEZ, Gabriel (1982): “Umberto D”. Entre Cachacos I. Obra Periodística. Bruguera, Barcelona: 475-477.

\footnotetext{
${ }^{11}$ Por otro lado, el mismo Piglia, cuando en su artículo quiere dar un ejemplo sobre la diferencia entre suspenso y sorpresa, retoma un diálogo de Hitchcock con Truffaut, pero en este texto los dos están hablando de cómo esta se da en el cine, y no en la literatura, y me temo que no sea exactamente lo mismo.
} 
HODGSON, Irene B. (2002): “The De-Chileanization of Neruda Il Postino". Pablo Neruda and the U.S. Culture Industry. Ed. Teresa Longo. Nueva York / Londres, Routledge: 97-113. DOI: https://doi.org/10.4324/9781315879727

JIMÉNEZ AGUIRRE, Gustavo (ed.) (2011-2014): Una selva tan infinita. La novela corta en México. Vols. I-II-III. México, Universidad Nacional Autónoma de México.

--- (ed.): La novela corta: una biblioteca virtual, http://www.lanovelacorta.com/ (última consulta: 30/06/2017).

MONTOYA, Pablo (2013): La música en la obra de Alejo Carpentier. Medellín, La Carreta Editoriales.

MUTIS, Álvaro (1988) [1973]: "La Mansión de Araucaíma". La muerte del estratega. Narraciones, prosas y ensayos. México, Fondo de Cultura Económica: 45-73.

--- (1989): "La irresponsabilidad del viajero". El Papel Literario de El Nacional. Caracas. En Carmen Bustillo: "Álvaro Mutis: parodia y autoparodia en La mansión de Araucaíma". Thesaurus XLIX/1 http://cvc.cervantes.es/lengua/thesaurus/pdf/49/TH_49_001_150_0.pdf (última consulta: 30/06/2017).

OLACIREGUI, Julio (1983): Présence du roman "gothique" dans la littérature latinoaméricaine: La Mansión de Araucaíma d'Alvaro Mutis. Tesis doctoral. París, Université La Sorbonne Nouvelle.

PIGLIA, Ricardo (2006): "Secreto y narración. Tesis sobre la nouvelle”. El arquero inmóvil. Nuevas poéticas sobre el cuento. Madrid, Páginas de Espuma. 187-205.

PREVITERA, Roberta (2014): Le cinéma dans la fiction Hispano-Américaine. Tesis doctoral. París, Université Paris-Sorbonne.

RAMOS, Luis Arturo (2011): "Notas largas para novelas cortas". Una selva tan infinita. La novela corta en México. Ed. Gustavo Jiménez Aguirre. Vol. I. México, Universidad Nacional Autónoma de México: 37-48.

ROCCO, Alessandro (2009): La scrittura immaginifica. Il film-scritto nella narrativa ispanoamericana del Novecento: Roma, Aracne.

--- (2014): García Márquez and the cinema. Londres, Tamesis.

RODRÍGUEZ AMAYA, Fabio (1996): “È possibile l'esistenza di un romanzo gotico nel tropico?". En Rosanna Casari, et alii. Testo letterario e immaginario architettonico. Milano, Jaca Book: 230-242.

--- (2000): El marinero y el río. Dos ensayos de literatura colombiana. Viareggio, Mauro Baroni Editore.

SHERIDAN, Guillermo (1976): "La vida, la vida verdaderamente vivida... Entrevista con Álvaro Mutis". Revista de la Universidad de México XXXI/3 (noviembre 1976): 25-37.

VARGAS LLOSA, Mario: "Mario Vargas Llosa y el cine". Disponible en YouTube: https://www.youtube.com/watch?v=e42dki6-oko (última consulta: 30/06/2017). 
(C) Stefano Tedeschi

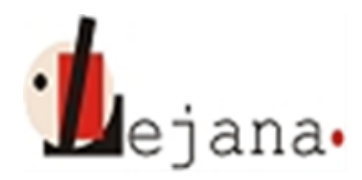

http://ojs.elte.hu/index.php/lejana

Universidad Eötvös Loránd, Departamento de Español, 1088 Budapest, Múzeum krt. 4/C 